\title{
Vanda v. West-Ward Pharmaceuticals: Good News for the Patent Eligibility of Diagnostics and Personalized Medicine, with Some Important Caveats
}

\author{
By CHRISTOPHER M. HOLMAN
}

I N Mayo V. Prometheus, decided in 2011, the U.S. Supreme Court declared patent ineligible claims directed towards diagnostic methods useful in the optimization of drug dosage for an individual patient, based on the Court's determination that the claims were directed towards a patent ineligible concept, i.e., a law of nature. ${ }^{1}$ The ruling represented a heightening of the bar when it came to the patenting of life science inventions, but the import of Mayo beyond pure diagnostic inventions of the type at issue in the case has remained an open question. In particular, what if a claim reciting a diagnostic test further includes a limitation requiring some action based on the outcome of that test? Would such a claim pass muster under Mayo? For example, the claims at issue in Mayo recited a method of testing a patient's blood for the level of a specific drug metabolite, with the result of the test being used to advise whether the dosage of the drug should be adjusted up or down. The obvious question in the wake of Mayo was whether the claim could have been saved by reciting an additional step of actually administering the drug to the patient at the adjusted dosage.

On April 13, 2018, the U.S. Court of Appeals of the Federal Circuit issued a decision in Vanda Pharmaceuticals $v$. West-Ward Pharmaceuticals International Limited that for the first time addresses this question head-on, and answers it in the affirmative. ${ }^{2}$ This is a welcome development for biopharmaceutical innovators, but it should be emphasized that this was a split decision, with one of the three judges authoring a dissenting opinion that quite plausibly

Christopher M. Holman is the Executive Editor of Biotechnology Law Report and a Professor at the University of Missouri-Kansas City School of Law. argues that the additional "action step" should have been found insufficient to render the claim patent eligible, particularly given the striking similarity between the underlying inventions claimed in Vanda and Mayo.

This Holman Report provides some background on the issues raised by Vanda, as well as an analysis of the decision and its significance moving forward, including some important caveats. In particular, while under Vanda the inclusion of an additional step of applying information gleaned from a recited diagnostic test appears sufficient to render the claim patent eligible, as a practical matter, it will also render the claim difficult, if not impossible, to enforce-at least outside the context presented in Vanda, in which the accused infringer is a generic drug company required by law to include on the proposed generic drug's label a recommendation that physicians perform the patented method in the course of administering or prescribing the drug.

\section{MAYO AND ITS AFTERMATH}

In Mayo, the Supreme Court considered a single representative claim, i.e., Claim 1 of U.S. Patent Number 6,355,623, which recites:

A method of optimizing therapeutic efficacy for treatment of an immune-mediated gastrointestinal disorder, comprising:

\footnotetext{
${ }^{1}$ Mayo Collaborative Servs. v. Prometheus Labs., Inc., 566 U.S. 66 (2012).

${ }^{2}$ Vanda Pharm. Inc. v. W.-Ward Pharm. Int'l Ltd., 887 F.3d 1117 (Fed. Cir. 2018) (an edited version of this decision is provided in this issue of BIOTECHNOLOGY LAW REPORT as a Case in Point).
} 
(a) administering a drug providing 6thioguanine to a subject having said immunemediated gastrointestinal disorder; and

(b) determining the level of 6-thioguanine in said subject having said immune-mediated gastrointestinal disorder,

wherein the level of 6-thioguanine less than about 230 pmol per $8 \times 10^{8}$ red blood cells indicates a need to increase the amount of said drug subsequently administered to said subject and wherein the level of 6-thioguanine greater than about 400 pmol per $8 \times 10^{8}$ red blood cells indicates a need to decrease the amount of said drug subsequently administered to said subject.

Note that while the Mayo claim does include a step (a) of administering the drug to a patient, this administration step occurs prior to performance of the diagnostic test, and is not an action based on the result of the test. Because of the nature of the test, which directly measures the level of drug metabolite (6-thioguanine) in the patient's body, it is of course a necessary prerequisite of the test that the patient be administered the drug. In Mayo, Justice Breyer characterized this "administering" steps as doing nothing more than "simply refer[ring] to the relevant audience, namely doctors who treat patients with certain diseases with thiopurine drugs." 3

The Supreme Court, and Federal Circuit before it, adopted the claim construction of the district court, which "construed the 'indicates a need' language found in the 'wherein' clause to mean 'when the identified metabolites reach the specified level, the doctor is warned or notified that a dosage adjustment may be required." ${ }^{4}$ The courts thus construed the claim as comprising three steps: (1) administer the drug to a subject; (2) determine metabolite levels; and (3) be warned that an adjustment in dosage may be required. Many, including this author, speculated that the outcome might have been different if the claim had explicitly recited a step of applying the "warning" by administering the drug post-determination at an adjusted dosage based on the information gleaned from the diagnostic test. If not, the prognosis for the patenting of personalized medicine inventions was not good.

In May 2016, the U.S. Patent and Trademark Office (PTO) published a document entitled Subject Matter Eligibility Examples: Life Sciences (the "PTO Examples"), which explicitly found that inclusion of an additional step of administering a drug to a patient in accordance with the results of a diagnostic test can render an otherwise patent ineligible diagnostic method patent eligible. ${ }^{5}$ In particular, Claim 2 of Example 29 of the PTO Examples, which is patent ineligible according to the PTO, recites:

A method of diagnosing julitis in a patient, said method comprising:

a. obtaining a plasma sample from a human patient;

b. detecting whether JUL-1 is present in the plasma sample by contacting the plasma sample with an anti-JUL-1 antibody and detecting binding between JUL-1 and the antibody; and c. diagnosing the patient with julitis when the presence of JUL-1 in the plasma sample is detected.

In contrast, Claim 6 of Example 29, which the PTO found to be patent eligible, recites:

A method of diagnosing and treating julitis in a patient, said method comprising:

a. obtaining a plasma sample from a human patient;

b. detecting whether JUL-1 is present in the plasma sample;

c. diagnosing the patient with julitis when the presence of JUL-1 in the plasma sample is detected; and

d. administering an effective amount of antitumor necrosis factor (TNF) antibodies to the diagnosed patient.

Furthermore, post-Mayo but prior to the publication of the PTO Examples, individual examiners began allowing diagnostic claims very similar to the Mayo claim, albeit with the inclusion of an additional drug administration step. For example, on November 19, 2013, U.S. Patent Number $8,586,610$ issued, with a Claim 1 reciting:

A method for treating a patient with iloperidone, wherein the patient is suffering from schizophrenia, the method comprising the steps of:

determining whether the patient is a CYP2D6 poor metabolizer by: obtaining or having obtained a biological sample from the patient; and

\footnotetext{
${ }^{3}$ Mayo, 566 U.S. at 78.

${ }^{4}$ Prometheus Labs., Inc. v. Mayo Collaborative Servs., No. CIV. 04CV1200JAHRBB, 2008 WL 878910, at *6 (S.D. Cal. Mar. 28, 2008).

${ }^{5}$ Available at https://www.uspto.gov/sites/default/files/ documents/ieg-may-2016-ex.pdf (last visited May 7, 2018).
} 
performing or having performed a genotyping assay on the biological sample to determine if the patient has a CYP2D6 poor metabolizer genotype; and

if the patient has a CYP2D6 poor metabolizer genotype, then internally administering iloperidone to the patient in an amount of $12 \mathrm{mg} /$ day or less, and

if the patient does not have a CYP2D6 poor metabolizer genotype, then internally administering iloperidone to the patient in an amount that is greater than $12 \mathrm{mg} /$ day, up to $24 \mathrm{mg} / \mathrm{day}$, wherein a risk of QTc prolongation for a patient having a CYP2D6 poor metabolizer genotype is lower following the internal administration of $12 \mathrm{mg} /$ day or less than it would be if the iloperidone were administered in an amount of greater than $12 \mathrm{mg} /$ day, up to $24 \mathrm{mg} /$ day.

This claim was ultimately found to be patent eligible in Vanda, as discussed below.

In Cleveland Clinic v. True Health Diagnostics, decided by the Federal Circuit on June 16, 2017, the court, on a motion for summary judgment, invalidated as patent ineligible three patents with claims directed towards diagnostic methods that allowed for an assessment of a test subject's risk of developing a complication of atherosclerotic cardiovascular disease, but did not include a step applying the information generated by the claimed diagnostic test. ${ }^{6}$ Claim 14 of U.S. Patent Number 7,222,552, granted on March 29,2007 , is representative of the invalidated claims:

A method of assessing a test subject's risk of developing a complication of atherosclerotic cardiovascular disease comprising:

determining levels of myeloperoxidase (MPO) activity, myeloperoxidase (MPO) mass, or both in a bodily sample of the test subject, said bodily sample being blood, serum, plasma, blood leukocytes selected from the group consisting of neutrophils and monocytes, or any combination thereof;

wherein elevated levels of MPO activity or MPO mass or both in the test subject's bodily sample as compared to levels of MPO activity, MPO mass, or both, respectively in comparable bodily samples obtained from control subjects diagnosed as not having the disease indicates that the test subject is at risk of developing a complication of atherosclerotic cardiovascular disease.

Interestingly, in Cleveland Clinic the accused infringer did not challenge the patent eligibility of
U.S. Patent Number 9,170,260, issued post-Mayo (October 27, 2015) as a continuation of the ' 552 patent.

Representative Claim 1 of the '260 patent recites:

A method for administering a lipid lowering agent to a human patient based on elevated levels of myeloperoxidase (MPO) mass and/ or activity comprising:

(a) performing an enzyme linked immunosorbent assay (ELISA) comprising contacting a serum or plasma sample with an anti-MPO antibody and a peroxidase activity assay to determine MPO activity in the serum or plasma sample;

(b) selecting a patient who has elevated levels of MPO mass and/or activity compared to levels of MPO mass and/or activity in apparently healthy control subjects; and

(c) administering a lipid lowering agent to the selected human patient.

The patent eligibility of the ' 260 patent was rendered moot by the court's decision on summary judgment that the patent was not infringed, as discussed further below. While the accused infringer's decision not to challenge the patent eligibility of the '260 patent implies acquiescence as to its compliance with Mayo, it also denied the Federal Circuit the opportunity to explicitly address the question. Less than a year later, however, the Federal Circuit was required to determine the patent eligibility of the ' 610 patent in Vanda, as discussed in detail below.

\section{VANDA}

Vanda $v$. West-Ward arose out of the appeal of a decision by a district court in Delaware in an Abbreviated New Drug Application (ANDA) lawsuit brought under the Hatch-Waxman Act. The drug at issue, iloperidone, is an atypical antipsychotic approved by the U.S. Food and Drug Administration (FDA) in 2009 for the treatment of patients with schizophrenia and marketed under the trade name Fanapt by Vanda, the owner of the drug's New Drug Application (NDA). Iloperidone is claimed as a composition of matter in U.S. Reissue Patent 39,198 ("the '198 patent"), which was filed in 2000 , but which claims priority as a continuationin-part of a patent application originally filed in

${ }^{6}$ Cleveland Clinic Found. v. True Health Diagnostics LLC, 859 F.3d 1352 (Fed. Cir. 2017). 
1989. With extensions, the ' 198 patent expired November 15,2016 . In the district court proceedings below, the parties stipulated to the infringement of Claim 3 of the '198 patent, and the court concluded that Claim 3 would not have been obvious; the parties did not appeal any determinations with respect to the now-expired '198 patent.

Even with extensions, Vanda's "primary patent" on the active ingredient only provided about seven years of exclusivity. But fortunately for Vanda, it also owns the ' 610 patent (presented above). This patent issued in 2013, after the generic drug company West-Ward had already filed its ANDA. The '610 patent claims priority to a 2004 provisional application, and with extensions will not expire until November 2, 2027. This amounts to almost 11 years of additional exclusivity, assuming the Federal Circuit's decision stands, i.e., assuming it is not overturned or revised en banc or by the Supreme Court.

The method claimed in the ' 610 patent represents an example of personalized medicine, employing a genetic diagnostic test to personalize the dosage of iloperidone in a manner that optimizes the drug's safety and efficacy for an individual patient. Iloperidone tends to cause QT prolongation, which is a prolongation of the time interval between the $\mathrm{Q}$ and $\mathrm{T}$ waves of the heart rhythm. QT prolongation can lead to serious cardiac problems, and is a particular problem for patients that metabolize the drug more slowly than normal due to a genetic predisposition to produce lower-than-normal levels of the enzyme cytochrome P450 2D6. The claimed method involves performing a genotyping assay on a biological sample taken from a patient in order to assess whether or not the patient is a poor metabolizer of iloperidone, and then internally administering iloperidone to the patient at a dosage commensurate with the patient's inherent ability to metabolize the drug, i.e., $12 \mathrm{mg} /$ day or less for poor metabolizers, $12-24 \mathrm{mg} /$ day for non-poor metabolizers, with a resultant lowering of the risk of QT prolongation in poor metabolizers. The benefit to patients of the method appears to be substantial; according to the Federal Circuit, FDA's decision to approve iloperidone was based, at least in part, on the improved safety of the drug provided by the invention.

The district court found that the proposed marketing of the generic iloperidone would induce infringement of the ' 610 patent, and that the ' 610 patent is not invalid, and enjoined West-Ward from engaging in the commercial manufacture, use, offer to sell, sale in or importation into the United States of generic iloperidone prior to the expiration of the '610 patent, and further ordered that the effective date of any FDA approval of West-Ward's ANDA shall be a date not earlier than the latest of the expiration of the ' 610 patent or any applicable exclusivities and extensions.

The district court also ruled that the asserted claims were not invalid as patent ineligible, obvious, or for failure to comply with the written description requirement. On appeal, the district court affirmed all grounds. This Report will only address the Federal Circuit's analysis of the patent eligibility issue.

The Federal Circuit applied the by now wellestablished Mayo/Alice two-step framework to determine patent subject matter eligibility under 35 U.S.C. $\S$ 101: (1) determine whether the claims at issue are directed to one of the patent ineligible concepts, i.e., a law of nature, natural phenomenon, or abstract idea; and (2) determine whether the claim incorporates additional elements, either individually or as an ordered combination, that transform the nature of the claim into a patent eligible application of that concept. ${ }^{7}$ The Supreme Court has described Step 2 as a search for an "inventive concept," i.e., an element or combination of elements that is sufficient to ensure that the patent in practice amounts to significantly more than a patent upon the patent ineligible concept itself. ${ }^{8}$

In a split decision, a two-judge majority held that under Step 1 of the framework, Vanda's claim is not directed to a patent ineligible concept, thereby obviating Step 2. The resolution of the issue at Step 1 of the analysis appears to have hinged on the majority's relatively stringent interpretation of the word "directed," with the judges emphasizing that "it is not enough to merely identify a patent-ineligible concept underlying the claim; we must determine whether that patent-ineligible concept is what the claim is "directed to."”

The real challenge for the majority was to distinguish Vanda's claim from the claims ruled patent ineligible by the Supreme Court in Mayo in view of their striking similarity.

The underlying inventions in Mayo and Vanda address the same fundamental problem, which is that different people metabolize drugs at different rates, and thus the optimal dosage of a drug will vary depending upon an individual's ability to metabolize that particular drug. A dosage that is appropriate for normal metabolizers, for example, will be too high

${ }^{7}$ Alice Corp. Pty. v. CLS Bank Int'l, 134 S. Ct. 2347, 2355 (2014) (citations omitted) (quoting Mayo v. Prometheus, 566 U.S. at 72-73, 75-79).

${ }^{8}$ Id.

${ }^{9}$ Vanda, 887 F.3d at 1134 . 
for slow metabolizers and result in adverse side effects. In both cases, the invention is based on the identification of a diagnostic test for distinguishing between individual patients who metabolize the drug at different rates, and optimal dosing regimens for the two categories of patients. In Mayo, the diagnostic test assays for the level of a metabolite of the drug in the patient's body subsequent to the administration of the drug, while in Vanda the test is a genotyping assay that determines the patient's ability to metabolize the drug based on the level at which the patient expresses the cytochrome P450 2D6 gene, which encodes an enzyme known to metabolize a large number of drugs, including iloperidone. It is difficult to see how the nature of the test distinguishes the two patents, since they are simply two different and established means for answering the same fundamental question, i.e., how fast does this individual patient metabolize the drug recited in the claim? The only real substantive difference between the claims, in my view, is that while the Mayo claim simply provides a diagnostic test that advises a patient (or her doctor) to adjust the dosage, the Vanda claim recites the additional step of using that information in adjusting the administration of drug to the patient.

The majority found that the inclusion of the drug administration step rendered Vanda's claim a patent eligible "novel method of treating a disease," as opposed to the patent ineligible "diagnostic method" claimed in Mayo. Although the representative Mayo claim does include a step of administering drug to a patient, the critical difference is that in Mayo the drug is administered as part of the diagnostic test; in order to measure metabolite, it is of course necessary to first administer the drug that is to be metabolized. Prior to the Supreme Court weighing in, the Federal Circuit had initially found this drug administration step sufficient to render the claim patent eligible. ${ }^{10}$ On appeal, the Supreme Court characterized the administration step as "simply refer[ring] to the relevant audience, namely doctors who treat patients with certain diseases with thiopurine drugs." ${ }^{11}$ In the words of the Vanda majority, "[a]lthough the representative claim in Mayo recited administering a thiopurine drug to a patient, the claim as a whole is not directed to the application of a drug to treat a particular disease." 12

The majority further pointed to the Supreme Court's statement in Mayo noting that "unlike, say, a typical patent on a new drug or a new way of using an existing drug, the [Mayo] claims do not confine their reach to particular applications of those laws." In my view, this statement in Mayo distinguishing between the diagnostic claims at issue in the case and a patent on a "new way of using an existing drug" provides the strongest support for the Vanda majority's decision. The majority emphasized that the Mayo claim "did not involve doctors using the natural relationship between the metabolite level and lessening 'the likelihood that a dosage of a thiopurine drug will prove ineffective or cause harm.""13

The Vanda majority went on to state that, "unlike the claim in Mayo, to the extent that preemption is a concern, the ' 610 patent claims do not 'tie up the doctors' subsequent treatment decisions." To my mind, this was one of the weaker aspects of the decision, but apparently what the court had in mind is that the Mayo claim is broader because it could be infringed by a doctor even if that doctor does not use the outcome of the diagnostic test by administering the drug to a patient at an adjusted dosage. Presumably, the majority felt obligated to arrive at this conclusion in order to distinguish Mayo. In fact, putting aside for a moment the reality that Mayo is Supreme Court precedent that the Federal Circuit is obligated to follow, I think that the patent owner in Mayo (Prometheus) made a convincing argument at the district court level that its claims were not preemptive of the purported law of nature, including multiple examples of uses of the correlation between metabolite level and optimal drug dosage that on their face would not infringe Prometheus's claims.

The Vanda majority also found support for its decision in CellzDirect, a 2016 Federal Circuit decision that upheld the patent eligibility of claims directed towards "a method of producing a desired preparation of multi-cryopreserved hepatocyte cells." ${ }^{14}$ As was the case in Vanda, CellzDirect resolved the question of patent eligibility at Step 1 of the framework, holding that the claims were directed to "not simply an observation or detection of the ability of hepatocytes to survive multiple freeze-thaw cycles, [but rather] to a new and useful method of preserving hepatocyte cells." In CellzDirect, the Federal Circuit emphasized that "the natural ability of the subject matter to undergo the process does not make the claim 'directed to' that natural ability." ${ }^{15}$ Otherwise, claims directed to actually "treating cancer with

\footnotetext{
${ }^{10}$ Prometheus Labs., Inc. v. Mayo Collaborative Servs., 581 F.3d 1336 (Fed. Cir. 2009).

${ }^{11}$ Mayo, 566 U.S. at 78.

${ }^{12}$ Vanda, 887 F.3d at 1134

${ }^{13} I d$. at 1135 (emphasis in original).

${ }^{14}$ Id. at 1135-56 (citing Rapid Litig. Mgmt. Ltd. v. CellzDirect, Inc., 827 F.3d 1042, 1050 (Fed. Cir. 2016)).

${ }^{15}$ CellzDirect, 827 F.3d at 1049.
} 
chemotherapy" or "treating headaches with aspirin" would be patent ineligible. ${ }^{16}$

Finally, the Vanda majority found that the Supreme Court's decision in Myriad is not relevant to the outcome of the case, since the Court in Myriad explicitly noted that "method claims" and "patents on new applications of knowledge about [particular] genes" were "not implicated by [Myriad]. ${ }^{17}$ I think this is correct; Myriad only addressed the patent eligibility of product claims directed towards isolated DNA segments, and its holding would not appear to create any binding precedent with respect to method claims such as those at issue in Vanda.

In conclusion, Vanda held:

At bottom, the claims here are directed to a specific method of treatment for specific patients using a specific compound at specified doses to achieve a specific outcome. They are different from Mayo. They recite more that the natural relationship between CYP2D6 metabolizer genotype and the risk of [QT] prolongation. Instead, they recite a method of treating patients based on this relationship that makes iloperidone safer by lowering the risk of [QT] prolongation. Accordingly, the claims are patent eligible. ${ }^{18}$

The court's determination of patent eligibility prompted a dissent from Chief Judge Prost, in which she complained that the majority's "efforts to distinguish Mayo cannot withstand scrutiny," and that the majority had improperly "conflate[d] the inquiry at step one with the search for an inventive concept at step two." ${ }^{19}$ Judge Prost does seem to raise some valid points. It is hard to distinguish between the discovery underlying the claims in Vanda and the purported law of nature identified by the Court in Mayo. In both cases, the invention is based on the discovery of a correlation between the rate at which a patient metabolizes a drug and optimal dosage, and identification of a diagnostic test for discerning the correlation. While the Vanda majority emphasized the specificity of the claims with respect to the compound, the optimal dosage, and the patients to be treated, as Judge Prost points out, the claims in Mayo also identified specific patients, a specific category of drug, and "the precise levels of concentration in question." 20

Judge Prost argued that, particularly given the close similarity between the inventions claimed in Mayo and Vanda, the majority had erred in finding that the invention was not directed toward a patent ineligible law of nature at Step 1 of the framework. She particularly faulted the majority for including the administration step in the analysis under Step 1, noting that in Mayo the Supreme Court had analyzed that claim's administration step as part of the Step 2 inquiry into "inventive concept." According to Judge Prost, there was nothing inventive about administering iloperidone to a patient, and so the claim should have been judged patent ineligible at Step 2 of the inquiry.

In my view, both the majority and dissenting opinions find support in Mayo. Applying the test for patent eligibility as literally set forth and applied in Mayo, one could plausibly conclude that the introduction of an additional step of administering the drug at a dosage adjusted according to the results of the diagnostic test does not change the outcome. However, by the same token, it is hard to see how any drug method of treatment claim could be found patent eligible under this approach. After all, if the interaction of a nonnaturally occurring drug with the human body is a patent ineligible law of nature, a position with which I strongly disagree, but which the Supreme Court accepted in Mayo, then how does taking advantage of that interaction by treating a patient with that drug constitute an "inventive concept"? But on the other hand, that is clearly not the outcome the Supreme Court intended; as the Vanda majority points out, Mayo explicitly states that drug methods of treatment and new uses of known drugs are patent eligible under the test. Thus, I think the Vanda majority has the better argument, since it applies the vaguely outlined Mayo test in a manner that achieves the outcome consistent with the Supreme Court's intent, i.e., new methods of using a known drug to treat a patient are patent eligible.

\section{VANDA'S SIGNIFICANCE MOVING FORWARD}

Vanda is without a doubt good news for innovators in molecular diagnostics and personalized medicine, and more importantly for patients who stand to benefit from such innovations, but the decision comes with a number of significant caveats. First off, is important to bear in mind that this might

\footnotetext{
${ }^{16} I d$.

${ }^{17}$ Vanda, 887 F.3d at 1136 (citing Association for Molecular Pathology v. Myriad Genetics, Inc., 569 U.S. 576, 595-96 (2013)).

${ }^{18} I d$.

${ }^{19} I d$. at 1140.

${ }^{20} I d$. at 1141 .
} 
not be the last word on the important question of whether inclusion of a step applying information generated by diagnostic test will as a general matter be sufficient to render a claim to a new diagnostic method patent eligible. Judge Prost's dissent provides a well-reasoned and entirely plausible interpretation of Mayo that, if shared by other members of the court, could temper, or even negate, the majority's decision. This might come in the form of a reversal of Vanda upon reconsideration by the en banc court, or through a subsequent decision by a different panel coming to the opposite conclusion with respect to a similar claim, along lines set forth by Judge Prost. Conceivably, the Supreme Court could even choose to get involved and overturn the panel's decision, although I think this would be unlikely.

On the other hand, I feel fairly optimistic that Vanda will stand and the Federal Circuit will, as a body, come to adopt the panel's relatively permissive interpretation of Mayo. The decision makes good policy, and I think is permitted under a plausible reading of Mayo, particularly given Mayo's sanctioning of method of treatment claims. It is consistent with the PTO's interpretation of Mayo, which I think clearly reflects a policy-driven interpretation of Supreme Court precedent. The Vanda majority decision was written by Judge Lourie, a former patent attorney at a pharmaceutical company, who I believe is the judge on the Federal Circuit most knowledgeable of and attuned to the needs of the innovative biopharmaceutical industry. His decision reflects, in my view, a policy-informed interpretation of Mayo that builds upon and bolsters the salutary effects of the court's earlier decision in CellzDirect.

Moreover, the reasoning of Vanda should render the decision generally applicable to most personalized medicine claims that recite the administration of a drug in a manner indicated by the results of a diagnostic test. There was nothing particularly factspecific about the court's decision. This was not a new drug, nor a new indication. It is, I think, significant that the majority decided the question of patent eligibility at Step 1 of the Mayo framework rather than at Step 2. If the determination of patent eligibility of claims of this type were to occur at Step 2, the court would be required to assess whether the drug administration step was inventive, on the one hand, or "routine/conventional" on the other. This could lead to a finding of patent ineligibility in cases in which the drug and its method of administration are not new-this is, of course, the outcome urged by Judge Prost. By shifting the determination to Step 1 , the majority was able to conclude that the claim is a patent eligible method of treatment without assessing the inventiveness of use of the drug in a method of treatment.

The more-significant caveat that comes with Vanda is that inclusion of a drug administration step will in many instances make it much more difficult, if not impossible, for a patent owner to prevail on a claim of infringement. In Vanda, the patent owner was the drug company that owned the NDA for the subject drug, iloperidone, and the finding of infringement depended critically on the fact that the claimed method was incorporated into the drug's FDA-approved label, which the generic company was required to copy in its own proposed label. The finding of infringement also hinged upon the fact that the accused infringer was a generic company attempting to market its version of the drug under an ANDA. If the accused infringer was not a competing generic drug company, the patent owner would have had a much more difficult time prevailing. For example, if the same patent claim had been owned by a diagnostic testing company that provided the genotyping test as a commercial service, it would have likely been difficult, if not impossible, to successfully assert the claim against a competing diagnostic testing company providing similar services.

For example, while Vanda suggests that the Mayo claims could have been rendered patent eligible by the inclusion of an additional step of administering the thiopurine drug at a dosage indicated by the results of the test for level of drug metabolite in the patient's blood, the inclusion of this additional step would have also in all likelihood precluded Prometheus from establishing Mayo's infringement. Although I have at times heard people criticize the drafter of Prometheus's claims for failing to include a step applying the information gleaned from the recited diagnostic tests, I do not think the omission was due to oversight. Rather, I strongly suspect that the drafter of the claims quite rationally believed that inclusion of this additional step would have rendered it impossible for the patent owner, Prometheus, to enforce the patent against the most likely target of a patent infringement suit, a competing diagnostic company like Mayo.

With the claims as written, Prometheus could have prevailed on a claim of infringement by proving that a competing diagnostic testing company performs the diagnostic tests in a manner that informs doctors and/or patients as to the need to adjust the dosage of a thiopurine drug. Not a particularly difficult thing to prove, given that is what diagnostic testing companies like Mayo do. But diagnostic companies generally do not administer drugs to patients, so the inclusion of a drug administration step in the claim creates a substantial, if not insurmountable, obstacle to enforcement. This was particularly 
the case at the time Prometheus drafted and prosecuted the claims asserted in Mayo, years before the en banc Federal Circuit issued its 2015 decision in Akamai $V$ substantially lowering the bar for proving direct infringement of a method claim under a scenario of joint/divided infringement. ${ }^{21}$

Prior to Akamai V, Federal Circuit precedent required, as a prerequisite to a finding of direct infringement, that the performance of all the steps in a method claim be attributable to a single entity. ${ }^{22}$ In order be attributable to a single entity, each step had to be performed either directly by the entity or by someone operating under the control or direction of that entity, i.e., under circumstances such that "there is an agency relationship between the parties who perform the method steps or when one party is contractually obligated to the other to perform the steps." 23 Doctors generally do not act as the agents of diagnostic companies, so under this standard it would be impossible to establish direct infringement by a diagnostic company of a claim reciting a drug administration step.

In Akamai $V$, the en banc Federal Circuit expanded the range of circumstances under which performance of a method step by one entity can be attributed to another. Under Akamai $V$, an agency relationship is not necessarily required. For example, the direction or control necessary to establish direct infringement can "be found when an alleged infringer conditions participation in an activity or receipt of a benefit upon performance of a step or steps of a patented method [by another] and establishes the manner or timing of that performance." 24 An entity can also be held "responsible for others' performance of method steps... where the actors form a joint enterprise." 25 "A joint enterprise requires proof of four elements: (1) an agreement, express or implied, among the members of the group; (2) a common purpose to be carried out by the group; (3) a community of pecuniary interest in that purpose, among the members; and (4) an equal right to a voice in the direction of the enterprise, which gives an equal right of control." 26

Still, even under the more relaxed Akamai $V$ standard, it is highly unlikely that a patent owner such as Prometheus would be able to prove that a diagnostic company like Mayo was directing or controlling the actions of doctors and patients, or involved in some sort of joint enterprise, and this inability would preclude a finding of direct infringement. While the patent owner might attempt to establish indirect infringement under a theory of inducement, it would be much more difficult in a case where the accused is a diagnostic testing company than it was for Vanda, where the accused infringer was a competing generic drug company.
In order to prove that a diagnostic company induced infringement under 35 U.S.C. § 271(b), a competing patent owner would have to establish direct infringement by someone, most likely a doctor, and also a specific intent on the part of the accused diagnostic company to induce infringement by that doctor. Under Akamai $V$, proving direct infringement by a doctor would not present an insurmountable challenge, as illustrated by the patent owner's success in doing just that in Vanda. In Vanda, the court found that the doctor had performed the "performing or having performed a genotyping assay" and "internally administering iloperidone to the patient" steps by virtue of ordering a genotyping assay and prescribing the drug for self-administration by the patient, respectively. The inclusion of the "having performed" language in the claim helped, but I think even if the claim had merely recited "performing a genotyping assay" the court would have likely found the limitation satisfied by the doctor's ordering of the test. But this is not a foregone conclusion, and a finding of direct infringement by a doctor will, as a general matter, depend upon the specific language of the claims and the nature of the doctor's actions.

The more difficult challenge for a patent owner seeking to hold a diagnostic company liable for inducing infringement of such a claim is the requirement that it "establish that the defendant possessed specific intent to encourage another's infringement and not merely that the defendant had knowledge of the acts alleged to constitute inducement." 27 In a case where the accused inducer of infringement is a generic drug company, proof of specific intent can be established by showing that the drug's label would "encourage, recommend, or promote infringement." In Vanda, for example, the court found that language on the proposed generic drug label (which, pursuant to FDA requirements, was identical to the language on Vanda's branded product) recommending that practitioners perform or have performed a genotyping assay to determine whether patients are poor metabolizers of the

${ }^{21}$ Akamai Technologies, Inc. v. Limelight Networks, Inc. (Akamai V), 797 F.3d 1020, 1022 (Fed. Cir. 2015) (en banc) (per curiam).

${ }^{22}$ Limelight Networks, Inc. v. Akamai Technologies, Inc., 134 S. Ct. 2111, 2117 (2014) (citing Muniauction, Inc. v. Thomson Corp., 532 F.3d 1318 (2008)).

${ }^{23}$ Limelight, 134 S. Ct. at 2116.

${ }^{24}$ Akamai V, 797 F.3d at 1023.

${ }^{25} \mathrm{Id}$.

${ }^{26} I d$.

${ }^{27}$ DSU Med. Corp. v. JMS Co., 471 F.3d 1293, 1306 (Fed. Cir. 2006) (en banc in relevant part). 
drug, and further recommending adjustment of the dosage for a poor metabolizer in a manner consistent with the language of the patent claims, constituted a recommendation that practitioners perform all of the claimed steps, thereby inducing infringement. ${ }^{28}$ Other recent Federal Circuit decisions have similarly found induced infringement by a generic company based on language on the drug label recommending performance of the steps of a patented method. ${ }^{29}$

In the case of an allegedly infringing diagnostic company, on the other hand, it will likely be very difficult to prove that the company has encouraged, recommended, or promoted a doctor to perform all of the steps of a claim that includes a drug administration step. An example of this can be seen in Cleveland Clinic Foundation, the case discussed above. Although the claims that included a drug administration step were not challenged for patent ineligibility, the Federal Circuit affirmed the district court's decision to dismiss Cleveland Clinic's induced infringement claims. The court pointed out that "mere knowledge of possible infringement by others does not amount to inducement," and that that Cleveland Clinic had failed to show the necessary "specific intent and action" to induce infringement of the patent by doctors.

In its complaint, Cleveland Clinic submitted an example of a lab report that the diagnostic company accused of inducing infringement provides to doctors who have ordered the diagnostic test recited in the claim, and argued that these reports were "sufficient to create the reasonable inference that a doctor who ordered such a report would rely on the results and would administer a lipid lowering agent where the results indicated that the patient had a cardiovascular disease risk." The court rejected this assertion, however, and found the lab report insufficient as a matter of law to constitute the necessary level of encouragement, recommendation, or promotion to satisfy the inducement standard, pointing out that Cleveland Clinic had alleged "no facts that suggest any connection between [the accused infringer] and doctors that may prescribe lipid lowering drugs," and that the accused infringer "does not sell or prescribe lipid lowering drugs to patients."

\section{CONCLUDING THOUGHTS}

In summary, Vanda is an important decision that, if followed, does much to alleviate the concern that Mayo has raised regarding the availability of effective patent protection for diagnostics and personalized medicine. However, the inclusion of a step applying knowledge gleaned from the diagnostic test, e.g., a drug administration step, can have serious negative repercussions in terms of the ability of a patent owner to enforce the patent. As a general matter, under current precedent, a diagnostic testing company that merely performs the test and provides results to a patient or health-care provider is not likely to be found infringing, particularly if the report is carefully worded as providing doctors with "information," as opposed to a "recommendation."

In fact, perhaps the only scenario under which such a claim appears likely to be infringed is that presented in Vanda, in which the patent owner holds the NDA on a drug, and the FDA-approved label (which must be copied by generic companies) recommends that physicians use the claimed diagnostic test in conjunction with administering or prescribing the drug to patients. It is also important that the language of the proposed generic label align with that of the patent claim; in Vanda the accused infringer was able to point to differences between the language of the claims and the label, as well as certain qualifications in the guidance provided by the label. Ultimately, the Vanda majority found the language of the label close enough to support a finding of inducement, but there have been a number of cases where courts have found that the label of a generic drug did not induce infringement when it did not provide the necessary direction or recommendation to perform the patented method. ${ }^{30}$ Outside this particular scenario, Mayo still seems to create a substantial impediment to the effect of patenting of new diagnostics and personalized medicine, and thus a disincentive to innovation in this important aspect of health care.

\footnotetext{
${ }^{28}$ Vanda, 887 F.3d at $1130-31$.

${ }^{29}$ See, e.g., Sanofi v. Watson Labs. Inc., 875 F.3d 636 (Fed. Cir. 2017), and Eli Lilly \& Co. v. Teva Parenteral Medicines, Inc., 845 F.3d 1357 (Fed. Cir. 2017).

${ }^{30}$ See, e.g., Takeda Pharm. U.S.A., Inc. v. W.-Ward Pharm. Corp., 785 F.3d 625 (Fed. Cir. 2015), and Warner-Lambert Co. v. Apotex Corp., 316 F.3d 1348 (Fed. Cir. 2003).
} 